\title{
The Summer Intensity Variations of [OI] 6300 A in the Tropics ${ }^{1}$
}

\author{
D. Barbier ${ }^{2}$ and F. E. Roach \\ Boulder Laboratories, National Bureau of Standards \\ and \\ W. R. Steiger \\ Hawaii Institute of Geophysics, University of Hawaii
}

(Received October 19, 1961)

\begin{abstract}
Intensity variations in May and June 1961 of the night airglow emission [OI] 6300 A are discussed, based on observations made at the Hawaii Institute of Geophysics Haleakala Observatory. The zenith variations are shown to be proportional to the product

$$
\left(f_{0} F_{2}\right)^{2} \times \exp \left(-\frac{h^{\prime} F-200}{41.3}\right)
$$

determined from ionospheric vertical soundings. Plots of the $6300 \mathrm{~A}$ intensity over the entire sky indicate a complicated pattern of localized regions of enhanced emission which seem to correspond to in situ changes. The photometric changes of intensity correspond to concomitant vertical movements of the nocturnal ionospheric $F$ layer.
\end{abstract}

\section{Introduction}

Photometric equipment for the study of the night airglow was installed at the Hawaii Institute of Geophysics Haleakala Observatory (HIGHO) in April of 1961 (see fig. 1 and table 1). Included are (a) a scanning birefringent filter photometer for the emissions [OI] $5577 \mathrm{~A}$, [OI] $6300 \mathrm{~A}$ and NaI 5890, 96A [Roach, Megill, Rees, and Marovich, 1958] and (b) a fixed (zenith) calibrating photometer with interference filters for the same three emissions plus a control centered near 5300 A [Purdy, Megill, and Roach, 1961]. The photometers are similar to those in regular use at the Fritz Peak (Colo.) Observatory of the National Bureau of Standards.

The scanning photometer covers the sky in a series of almucantar sweeps (zenith angles: 80, 75, 70, $60,40^{\circ}$ ) plus the zenith. Five minutes are required for a complete survey in each of the three colors so that the time interval between successive surveys for a given color is $15 \mathrm{~min}$. In this paper we report on a study of the intensity variations of $6300 \mathrm{~A}$ for 14 nights during the May-June 1961 observing period.

The observing conditions at HIGHO are such as to yield a high percentage of photometrically useful skies. A previous study [Steiger and Little, 1958]

1 Contribution No. 32, Hawaii Institute of Geophysics.

2 On leave from L'Institut d'Astrophysique (Paris), at the Boulder Laboratories of the National Bureau of Standards during the summer of 1961. of the daytime sky transparency has shown that during about 70 percent of the time the clouds are below the top of the mountain all or part of the day and the atmosphere is extremely transparent. At night the clouds usually fall even lower or completely dissipate. During the first three months of the present program photometric observations were possible during more than 70 percent of the scheduled observing time.

\section{Summary of Some Earlier Studies}

Six separate and distinct components of upper atmosphere [OI] $6300 \mathrm{~A}$ emission have been identified: (1) the polar aurora, (2) the twilight enhancement, (3) the western sheet, (4) the subpolar sheets, (5) the tropical arc, and (6) the paratwilight phenomenon. They have been described in detail by Barbier [1961].

Barbier and Glaume [1960] have reported the existence of a 6300 A tropical arc at Tamanrasset for some eight months of the year centered on midwinter. The arc is one of a pair located on isoclines $\pm 30^{\circ}$ (dip latitudes $\pm 16^{\circ}$ ). Triangulation based on observations from an airplane and from Tamanrasset indicates that the height varies between 240 and $400 \mathrm{~km}$ [Barbier, Weill, and Glaume, 1961].

Observations during the summer have been made at Tamanrasset only with a fixed-position photometer. Barbier [1957] has reported that the $6300 \mathrm{~A}$ intensity level is in general rather low but that occasional increases in intensity as large as tenfold 


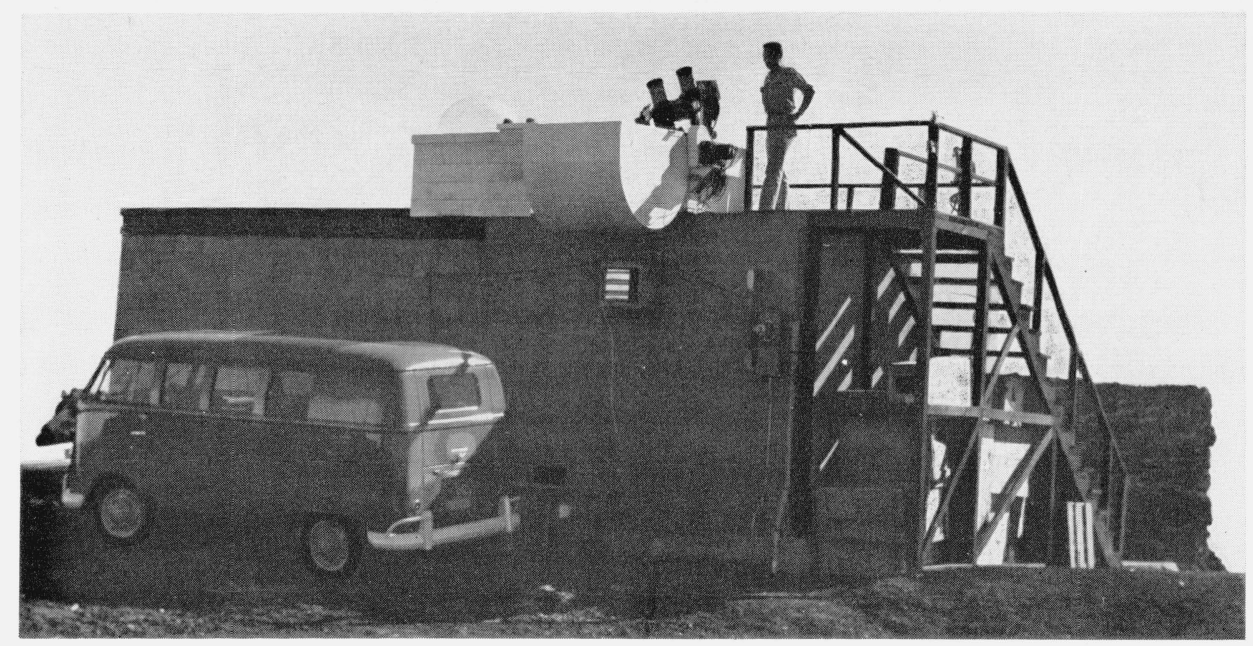

Figure 1. The Hawaii Institute of Geophysics, Haleakala Observatory airglow station.

Table 1. The Haleakala Station

\begin{tabular}{|c|c|}
\hline $\begin{array}{l}\text { Geographic Longitude_ } \\
\text { Geographic Latitude_-- } \\
\text { Geomagnetic Latitude } \\
\text { Dip Latitude } \\
\text { Dip } \\
\text { Altitude }\end{array}$ & $\begin{array}{l}156^{\circ} 16^{\prime} \mathrm{W} \\
20^{\circ} 43^{\prime} \mathrm{N} \\
21^{\circ} \mathrm{N} \\
22^{\circ} \mathrm{N} \\
39^{\circ} \\
10.012 \text { ft A. S.L. }\end{array}$ \\
\hline
\end{tabular}

occur over about 2 -hr periods. It was impossible to infer any kind of spatial structure from these Tamanrasset summer observations.

\section{Zenith Observations of $6300 \mathrm{~A}$ at HIGHO}

In figure 2 we show plots of $6300 \mathrm{~A}$ zenith intensities versus time for three nights between May 22/23 and June 19/20. As Barbier found for Tamanrasset, we note the frequent, though not universal, occurrence of well-defined intensity maxima. The times of maximum seem to be distributed in a more or less random fashion and the mean of all the observations gives an almost constant intensity after 2200 (fig. 3).

\section{Comparison of Zenith 6300 A Intensities With Ionospheric Changes}

A mechanism thought to be effective in reducing the electron concentration of the $F$ region is an ionatom exchange followed by a dissociative recombination [Bates and Massey, 1946]

$$
\begin{aligned}
& \mathrm{O}_{2}+\mathrm{O}^{+} \rightarrow \mathrm{O}_{2}^{+}+\mathrm{O} \\
& \mathrm{O}_{2}^{+}+e \rightarrow \mathrm{O}^{*}+\mathrm{O}^{* *} .
\end{aligned}
$$

In the $F$ region reaction 1 a controls the rate of the process. Reaction $1 \mathrm{~b}$ is effective in reducing the electron concentration and at the same time yields excited oxygen atoms capable of emitting either $6300 \mathrm{~A}$ or $5577 \mathrm{~A}$.
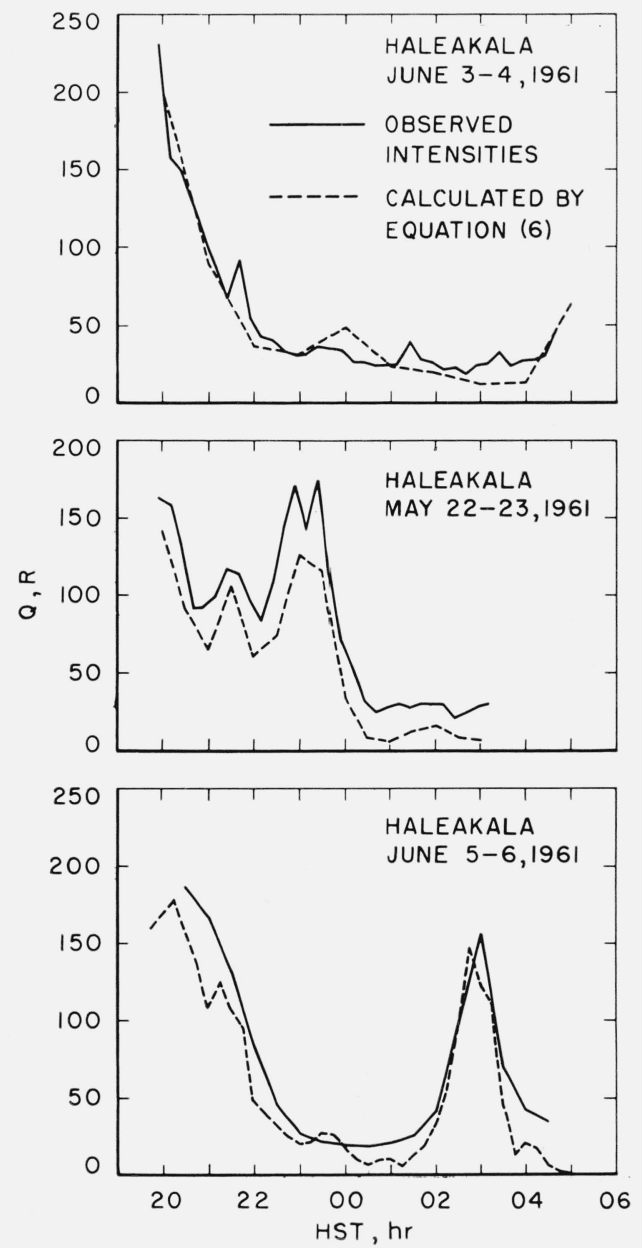

Figure 2. Plots of 6300 A zenith intensities versus time for three nights.

[(a) Quiescent conditions. (b) Enhanced conditions before midnight. (c) Enhanced conditions after midnight; unit of intensity throughout this paper is the Rayleigh.] 


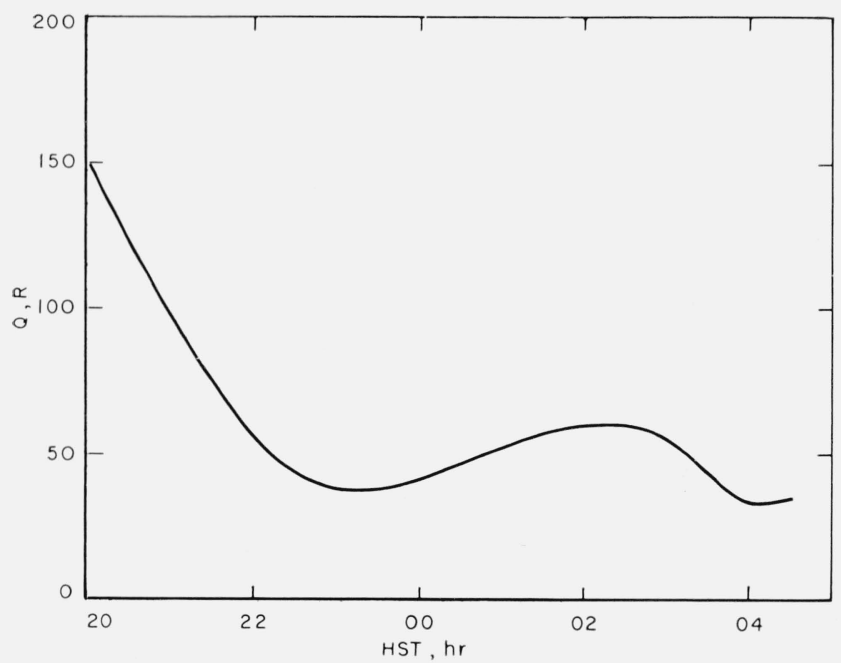

Figure 3. Mean of 6300 A zenith intensities versus time for 14 nights.

Another pair of reactions which can result in emission of $6300 \mathrm{~A}$ (but not $5577 \mathrm{~A}$ ) is

$$
\begin{aligned}
& \mathrm{N}_{2}+\mathrm{O}^{+} \rightarrow \mathrm{NO}^{+}+\mathrm{N} \\
& \mathrm{NO}^{+}+e \rightarrow \mathrm{N}^{*}+\mathrm{O}^{*} .
\end{aligned}
$$

For either $1 \mathrm{a}, 1 \mathrm{~b}$, or $2 \mathrm{a}, 2 \mathrm{~b}$, the total emission $Q$ of $6300 \mathrm{~A}$ is approximately given by

$$
Q=\int_{h_{0}}^{\infty} \mathrm{N} n d h
$$

where $\mathrm{N}$ is the concentration of $\mathrm{O}_{2}\left(\right.$ or $\left.\mathrm{N}_{2}\right), n$ is the concentration of electrons and $h_{0}$ is the beight at which the process becomes effective.

Barbier [1957] has suggested that an equation of the form

$$
Q=A\left(f_{0} F_{2}\right)^{2} e^{-\frac{\left(h^{\prime} F\right)-200}{H}}
$$

is a reasonable approximation to eq (3). In comparing the predictions of eq (4) with the $6300 \mathrm{~A}$ intensities at the Haute Provence Observatory (latitude $44^{\circ} \mathrm{N}$ ) he found a "statistical" agreement. Working near the equator (Lwiro, latitude $2.3 \mathrm{~S}$ geographic), A. and D. Delsemme [1960] found that an equation like (4) gave an excellent representation of the $6300 \mathrm{~A}$ zenith intensities.

In a detailed study of the 6300 .A zenith intensities at Tamanrasset, Barbier [1961] found that the following equation ${ }^{3}$ represented the observations for the May 1957-January 1960 period

$$
Q=87+2.35\left(f_{0} F_{2}\right)^{2} e^{-\frac{h^{\prime} F-200}{41.3}} .
$$

${ }^{3}$ In the paper by Barbier [1957] the parameters in this equation were slightly different. New parameters result from a least squares solution using the same data as the preliminary treatment.

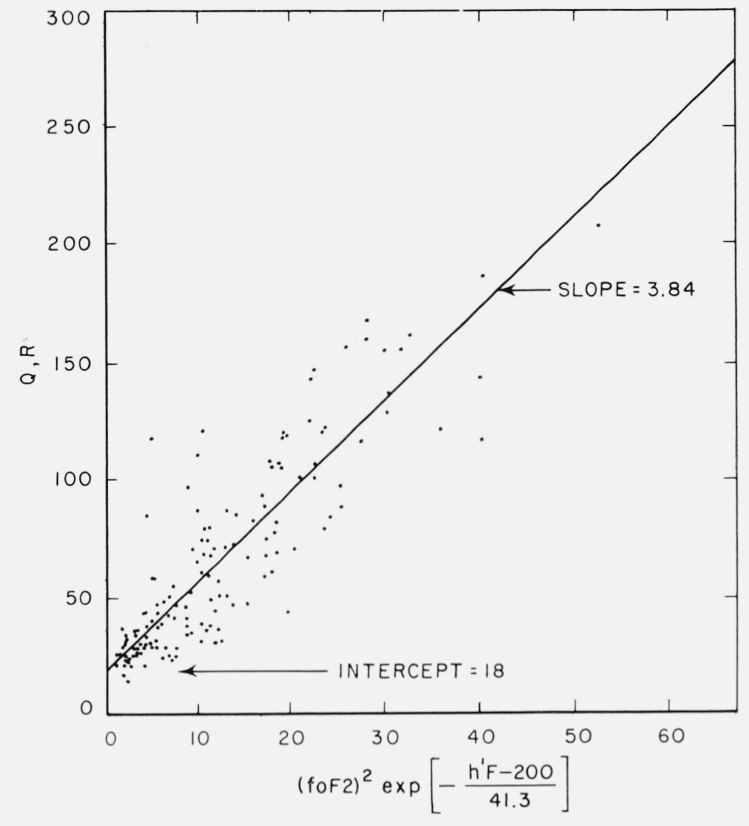

Figure 4. Observed intensity versus empirical formula $\left(\mathrm{f}_{0} \mathrm{~F}_{2}\right)^{2} \exp \left(-\frac{\mathrm{h}^{\prime} \mathrm{F}-200}{41.3}\right)$.

The additive constant may be the result of a component of $6300 \mathrm{~A}$ emission not due to recombination in the $F$ region.

We now turn to our current observations from HIGHO. In the first approximation we adopt a scale height of 41.3 (as for Tamanrasset). In figure 4 is shown a plot of $Q$ versus $\left(f_{0} F_{2}\right)^{2} e^{\frac{h^{\prime} F-200}{41.3}}$ from which we derive

$$
Q=18+3.84\left(f_{0} F_{2}\right)^{2} e^{-\frac{h^{\prime} F-200}{41.3}} .
$$

The difference between the additive constant, 18 , for HIGHO for the present short summer series and the 87 for the three complete years of Tamanrasset observations is probably real, since the Tamanrasset data show that this "constant" is much smaller in summer than in winter.

The ratio of the coefficients in the second terms of $(5)$ and $(6)$ is $3.84 / 2.35=1.6$. This may well be accounted for by the inherent difficulty in making absolute photometric calibrations.

In figure 2 we have included plots of predicted intensity of $6300 \mathrm{~A}$ (omitting the additive term) for comparison with the observations.

\section{All-Sky Representations of the Data}

From the photometric records obtained by the sky surveys described earlier in this paper, it is possible to construct diagrams which, as a crude approximation, may be considered as isophotal maps of the sky. In the process one must make corrections for the atmospheric scatter and extinction and for the distortion introduced by the geometry of the emission layer. 
(a) Absorption and scattering. We wish to make corrections to the observed intensity, $I_{0}$, so as to eliminate the effects of absorption and scattering and obtain an intensity $I$ which is the intensity that would be observed if there were no atmosphere below the emitting layer. One of us [Barbier, 1944] has shown that a first approximation to $I$ which is certainly very good at $6300 \mathrm{~A}$ is

$$
I=I_{0} e^{-m \tau_{2}}+J\left(1-e^{-m \tau_{1}}\right)
$$

where $J$ is a mean intensity over the entire sky and ground, $m$ is the air mass referred to zenith air mass, $\tau_{1}$ is the extinction coefficient due to scattering and $\tau_{2}$ is the extinction coefficient due to both scattering and absorption. We have taken for $\tau_{1}$ the coefficient relative to Rayleigh scattering, to which we have added the ozone absorption coefficient to get $\tau_{2}$.

We have approximated $J$ by

$$
J=\frac{1}{4 \pi} \int I_{0} d \omega
$$

This gives a value slightly too small because $I_{0}$ is smaller than the intensity at midlayer altitude. Moreover, $J$ should be increased by a certain factor to take into account ground reflection. Thus, we have multiplied $J$ by the factor 1.4.

(b) Geometry of the emission layer. Ideally we should like to derive from our observations an isophotal sky map which shows as each point on the map the local zenith intensity, that is, the intensity as would be observed by a photometer directly below that point. If the emitting layer were a spherical shell of constant height above the earth and relatively thin compared to its height, one could derive the local zenith intensity from the observed slant in-

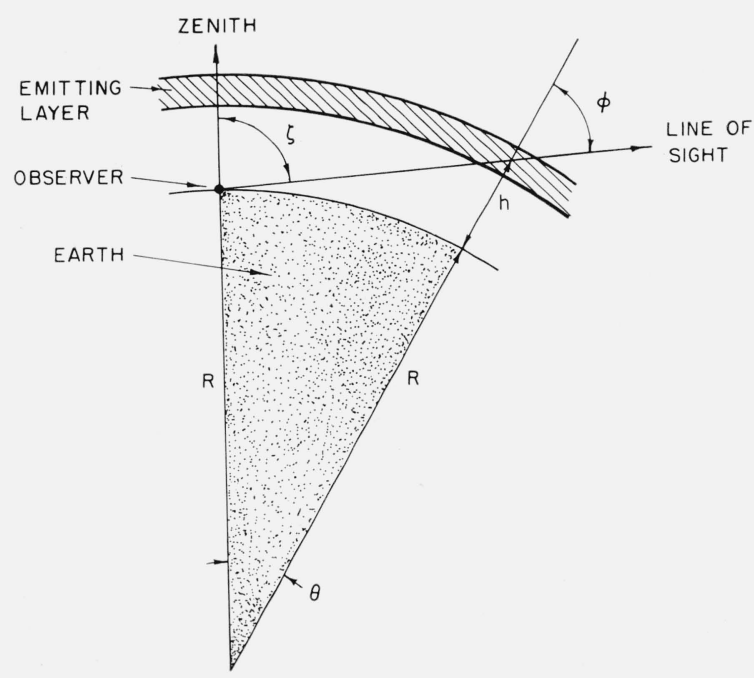

Figure 5. Geometry of the emitting layer when layer is horizontal. tensity by multiplying the latier by the factor cos $\phi$, where $\phi$ is the angle between the line of observation and the local vertical at the emitting layer.

From figure 5 it is seen that $\sin \phi=\left[\frac{R}{R+h}\right] \sin \zeta$ where $R$ is the radius of the earth, $h$ the height above the earth of the emitting layer, and $\zeta$ the zenith angle from the observer.

We did not, however, use the $\cos \phi$ factor because of the uncertainties in the corrections for scattering and absorption (reflection from the ground, thickness of the ozone layer, and scattering by particles were not considered at all). Rather, we determined an empirical factor $\gamma$ to be used instead of $\cos \phi$, the ratio $\frac{\gamma}{\cos \phi}$ taking into account the uncertainties in the above reduction for scattering and absorption.

The factor $\gamma(\zeta)$ was derived from the comparison of observations made at the zenith and at zenith distance $\zeta$. Only values corresponding to a geometrically simple layer were used. That is, values before 2055 or after 0410 (twilight effects) were not used, nor were those around the times of $6300 \mathrm{~A}$ enhancements. For the intensity at zenith distance $\zeta$, the mean of two values observed east and west was used because the general trend of the lines of equal intensity is to be oriented east-west under normal conditions.

The intensities at zenith distance $\zeta$ were found to be statistically proportional to the zenith intensities, the spread being not too large. A plot for $\xi=40^{\circ}$ is shown in figure 6 . The desired value of $\gamma$ is the reciprocal of the slope of the median line. The values of the $\gamma$ 's thus obtained and the values of $\cos \phi$ computed for $h=300 \mathrm{~km}$. are given in table 2 . The intensities have been multiplied $b_{y} \gamma$ and then entered into sky maps and isophotal contours drawn in. A number of these are shown in figure 7 .

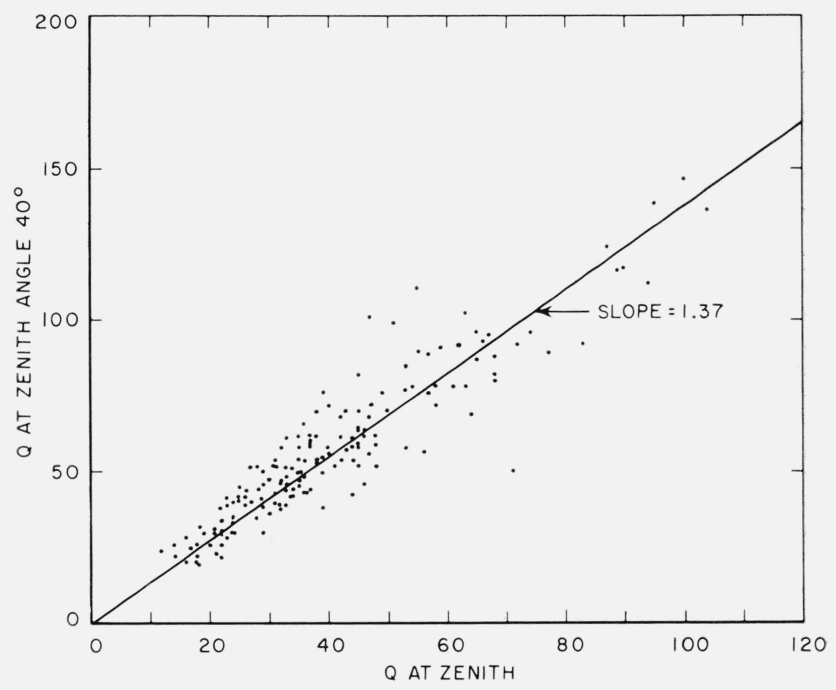

FIGURE 6. Intensities at zenith angle $40^{\circ}$ versus zenith intensities. 
TABLE 2

\begin{tabular}{c|c|c|c|c|c|c}
\hline$\zeta$ & $80^{\circ}$ & $75^{\circ}$ & $70^{\circ}$ & $60^{\circ}$ & $40^{\circ}$ & $0^{\circ}$ \\
\hline$\gamma \ldots \ldots$ & 0.243 & 0.284 & 0.365 & 0.472 & 0.730 & 1.000 \\
\hline $\cos \phi(h=300)$ & .340 & .386 & .441 & .562 & .789 & 1.000 \\
\hline
\end{tabular}

(c) Interpretation of the representations. The graphs constructed according to the procedures outlined here would show the isophotal contours of local zenith intensity only in the case of a thin layer of constant height. In the present situation, however, there is a considerable nonuniformity of height, as disclosed by triangulation in Tamanrasset or by the relationship to the ionospheric $h^{\prime}$ parameter. This nonuniformity in height produces two effects which introduce distortions into the graphs.

A first effect is due to the fact that the layer is not horizontal when there are changes in height. The slant intensity correction factor $\gamma$ is therefore no longer correct. If the component of the tilt of the layer in the vertical plane of observation is $i$, as shown in figure 8 , then the correction factor to $\gamma$ could be approximated by

$$
\frac{\cos (\phi+i)}{\cos \phi}
$$

The variation in altitude for the emission layer can be as large as $100 \mathrm{~km}$, and, anticipating our results on the dimensions of the enhanced regions, this change can take place in a horizontal distance of about $500 \mathrm{~km}$. Thus, $i$ can be as large as $\pm 12^{\circ}$. If $\zeta=75^{\circ}$, we have from the preceding table $\phi=67^{\circ}$, and the correction factor for $\gamma$ comes out to be about 0.5 for $+12^{\circ}$ and 1.5 for $-12^{\circ}$, which are not negligible corrections.

The second effect is a geometrical distortion which arises from the fact that the angle $\theta$ in figure 5 depends on the height, $h$, of the layer as well as the zenith angle, $\zeta$. Thus, if we plot the intensity of a region which is at a height of $200 \mathrm{~km}$ as though it were at a height of $300 \mathrm{~km}$, the angle $\theta$, or the distance from the center of the graph at which this point is plotted, will be too large by a factor of approximately $3 / 2$. To avoid this distortion, then, one should consider the height of the emission layer at each point.

We could consider taking this effect into account by means of the relationship between the intensity and the ionospheric parameters (especially with $h^{\prime} F$ ) as will be shown.

For instance, figure 9 shows $f_{0} F_{2}$ and $h^{\prime} F$ values for the night of June $5 / 6,1961$, as well as the observed intensity of $6300 \mathrm{~A}$. At time 0315 there is a big drop in the $h^{\prime} F$ value and $f_{0} F_{2}$ has a rather weak maximum at 0230 . The $6300 \mathrm{~A}$ enhancement was observed to reach a maximum at 0315 and this shows that $h^{\prime} F$ is the dominating factor in the emis-

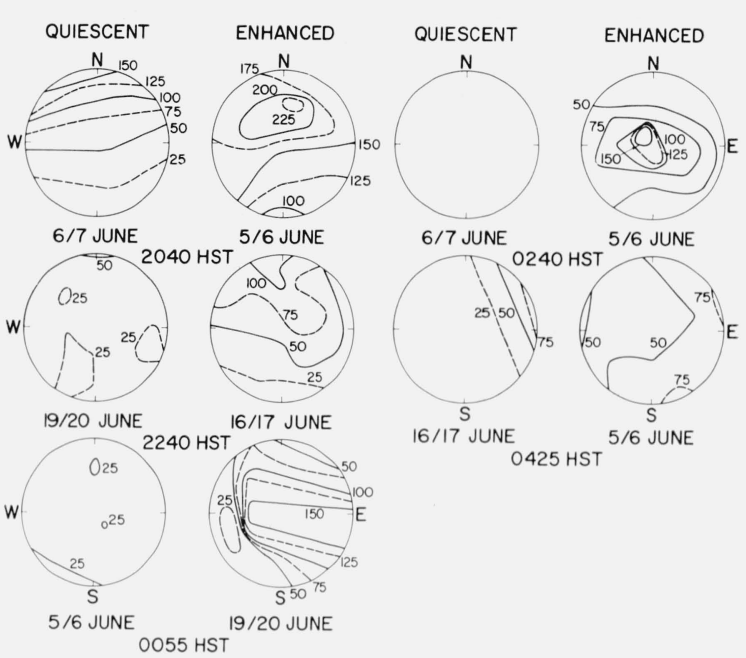

Figure 7. Isophotal sky representations for quiescent and enhanced conditions.

(Numbers on contours in Rayleighs.)

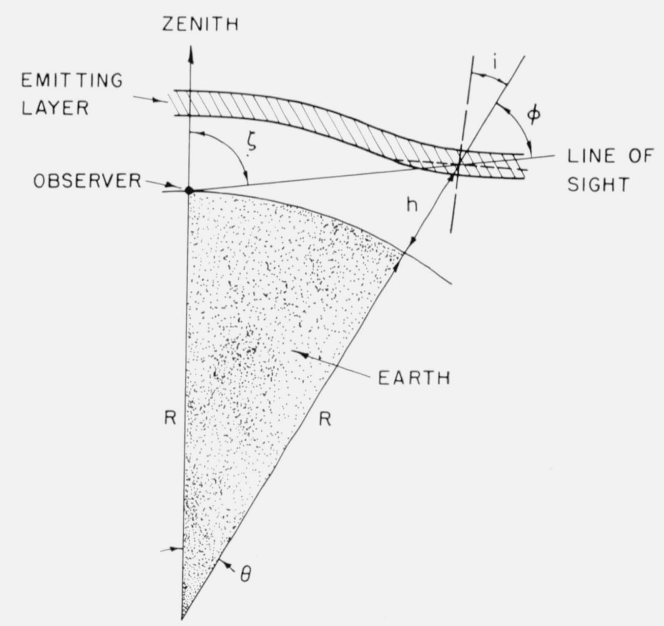

Figure 8. Geometry of the emitting layer when layer is tilted.

sion of $6300 \mathrm{~A}$. Accordingly it is possible to derive approximate heights by computation of $h^{\prime}$ from. $Q$ allowing for the fact that both $h^{\prime}$ and $Q$ are known at the zenith of the observing station. If we denote the latter by $h_{0}^{\prime}$ and $Q_{0}$ and neglect the constant term in $Q$, we get

$$
\frac{h^{\prime}-h_{0}^{\prime}}{41.3}=\log _{e} \frac{Q_{0}}{Q} .
$$

The true altitude of the emitting layer being most probably of the order of $h^{\prime}+41.3 \mathrm{~km}$, it would be possible to derive for each observed point of the layer its altitude and to report on a true map its corresponding intensity. 

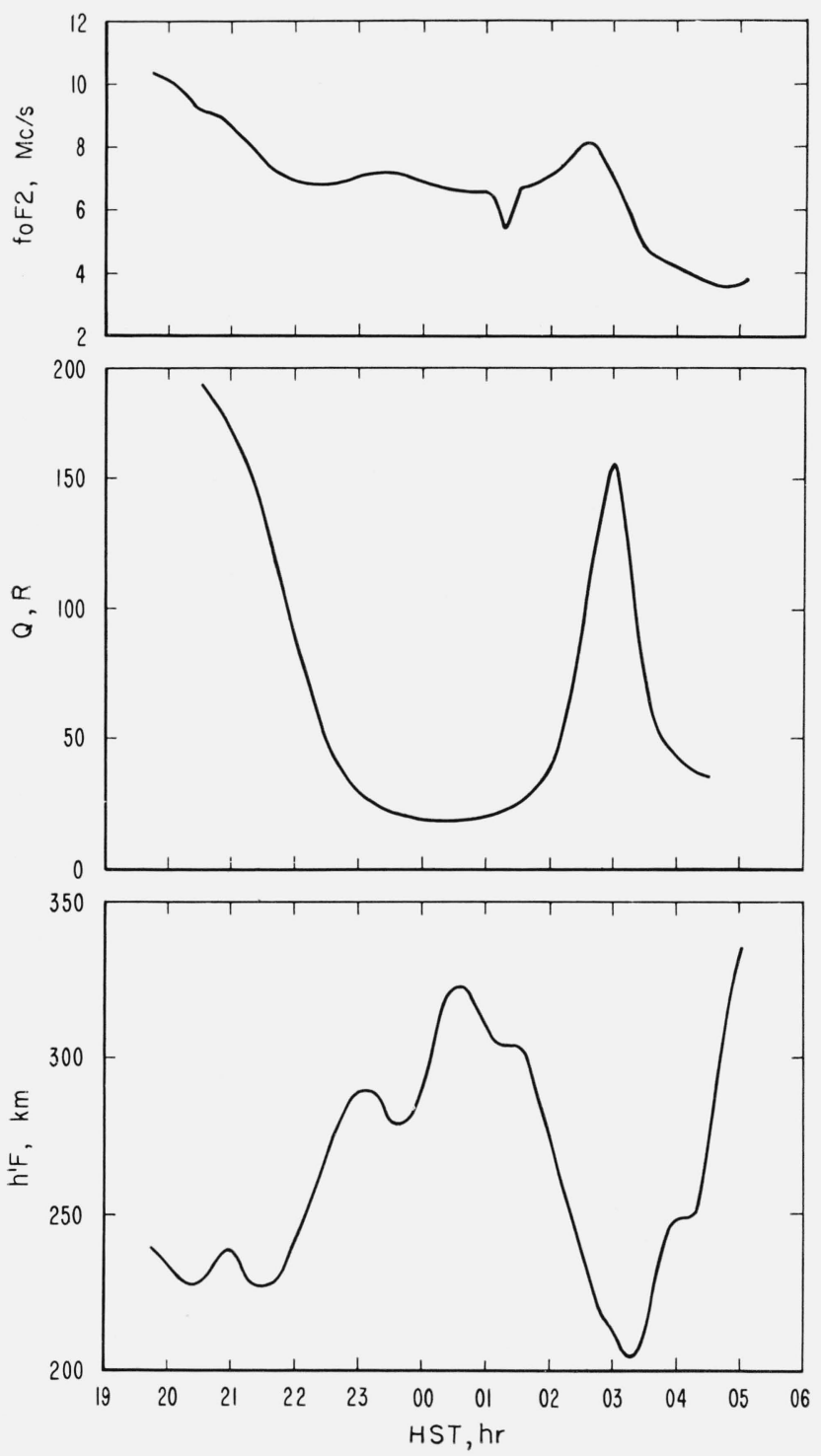

Figure 9. $\quad \mathrm{f}_{0} \mathrm{~F}_{2}$ and $h^{\prime} F$ for Kihei, Maui, and Q(6300) for Haleakala, Maui, during night of June 5/6, 1961.

We have not drawn maps according to this rather sophisticated procedure. Thus, one should keep in mind that the representations given in this paper are of an approximate nature.

\section{Description of the 6300 A Emission Layer}

In figure 7 are reproduced a number of the isophotal representations. For each time we give two graphs, one corresponding to quiescent conditions and the other to enhanced conditions.

(a) Quiescent conditions. At the beginning of the night we observe mostly the "western sheet" " to the NNW, slightly disturbed by the end of twilight. One should remark that its maximum intensity is not in the azimuth of the sun and thus cannot be

${ }^{4}$ La nappe occidentale in Barbier [1961]. confused with a pure twilight effect. Later in the night, after 2200 let us say, not much structure is left in the layer, whose intensity is decreasing slowly. At 2400 the intensity is everywhere less than 25 rayleighs and remains constant, within experimental errors. The mean intensity is about 14 rayleighs, and is of the same order as the constant term in the formula relating photometric and ionospheric data. This intensity remains practically constant as long as dawn is not appearing.

The first effect of morning twilight is apparent at 0400 at zenith distances of 75 to $80^{\circ}$. At 0425 it is readily seen and the azimuth of maximum intensity is in the azimuth of the sun.

(b) Enhanced conditions. Enhanced conditions are characterized by the spottiness of the graph. Generally there is only one spot. Sometimes this spot is quite elongated in the $\mathrm{E}-\mathrm{W}$ direction (June 5/6, 0240; June $19 / 20,2255$ ) and one could even speak of a short arc. Sometimes the contour of the spot is rather irregular and if elongated, it can be in any direction. Sometimes the center of the spot is obviously outside the graph. Linear dimensions of the spots (at middle intensity) are of the order of 500 to $1000 \mathrm{~km} .^{5}$

To illustrate the distortion discussed in section 5 (c) we have drawn in figure 10 the intensity of the 6300 A emission layer for June 19/20 at 0055 along $\mathrm{E}-\mathrm{W}$ line (curve A) assuming the true height to be $270 \mathrm{~km}$ ( $h^{\prime} F=230 \mathrm{~km}$ at zenith). The horizontal scale is distance along the surface of the earth from

${ }^{3}$ For a height of $300 \mathrm{~km}$, the diameter of the circles in figure 7 is about $1100 \mathrm{~km}$.
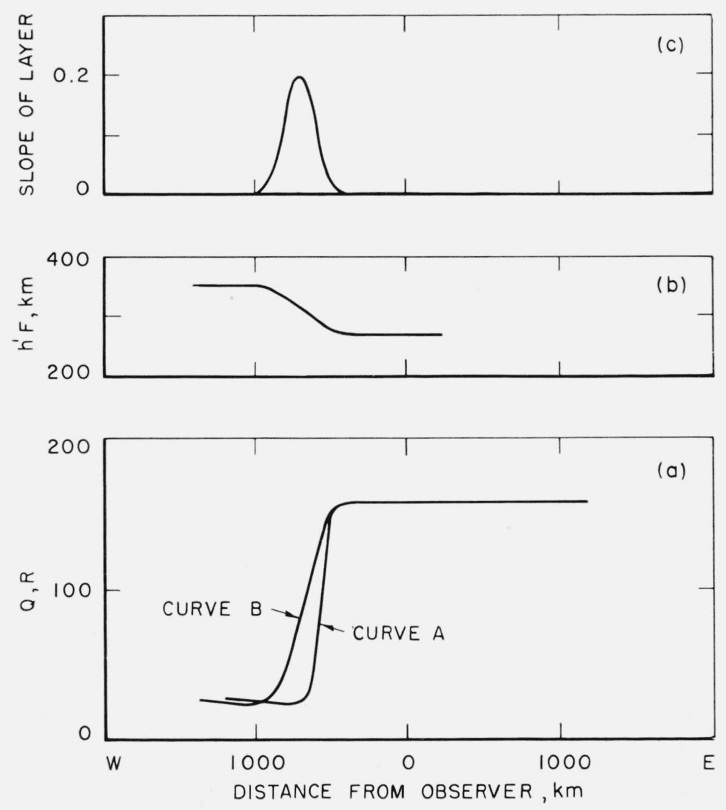

Figure 10. (a) Intensity of $6300 \mathrm{~A}$ emission along $\mathrm{E}-\mathrm{W}$ line, June 19/20, 1961, 0055 HST.

[Curve A: as observed. Curve B: corrected for height and tilt of emitting layer. (b) Height of emitting layer. (c) Slope of emitting layer.] 
the observing point. If now we compute the actual height of the layer from eq (10) and then correct the intensity for the tilt of the layer according to eq (9) and finally plot on a true horizontal scale, we arrive at curve $\dot{B}$. We see that the large change in intensity and altitude take place not in a distance of $200 \mathrm{~km}$ as shown in the uncorrected graph, but rather in $500 \mathrm{~km}$.

During the observing period there has generally been a spot at the beginning of the night and it has always been to the north of the station.

There has generally been another spot after midnight, sometimes rather far to the south, thus not showing in the zenith intensities. Though this spot was occasionally seen to the north, it was more often observed to the south of the station. Near the end of the night a spot has seldom been seen and, when present, it was generally a weak one.

\section{Evolution of the Spots}

An inspection of a succession of circle plots gives an impression that a spot shows no systematic motion such as, for instance, it would show if it were fixed in space, the earth rotating below (local time phenomenon).

It is possible to show that this impression is correct. We plot at each point on a sky map the time when the intensity is highest (near the time of maximum disturbance). Figure 11 shows the result for the night June 19/20. It is immediately obvious that in many points the intensity is a maximum at 0055. It is interesting to note that the contour of the line circling the area where the maximum intensity happened at 0055 (fig. 11) agrees with the zone of maximum intensity at that time (fig. 7). The spot did not come from the east, for instance, but formed and developed as a whole. The intensity reached a maximum at 0125 in an adjacent large region (unfortunately there were no observations at 0110) and this means that the spot after its formation spread toward the north. Times of maximum intensity rather different from 0055 or 0125 are found in regions of weak intensities and are probably unrelated to the evolution of the spot itself. It has been found that this behavior is rather general for other nights as well.

The spots are not really fixed in position, but their displacements are erratic and may occur by jumps. That is, between two surveys separated by $15 \mathrm{~min}$ in time, the position of the spots may change in a manner which is not predictable by earlier surveys.

In a spot showing a distinct nucleus, a second nucleus could form and become more intense as the first one declines. All appearances give an idea of a phenomenon not unlike a rather unstable cathodic spot.

In terms of the ionospheric relationship of eq (6) these photometric observations indicate that localized regions in the nocturnal $F$ layer undergo erratic changes in eff ective height from about 250 to $350 \mathrm{~km}$ over time intervals of about an hour. This corresponds to a vertical speed of about $30 \mathrm{mps}$.

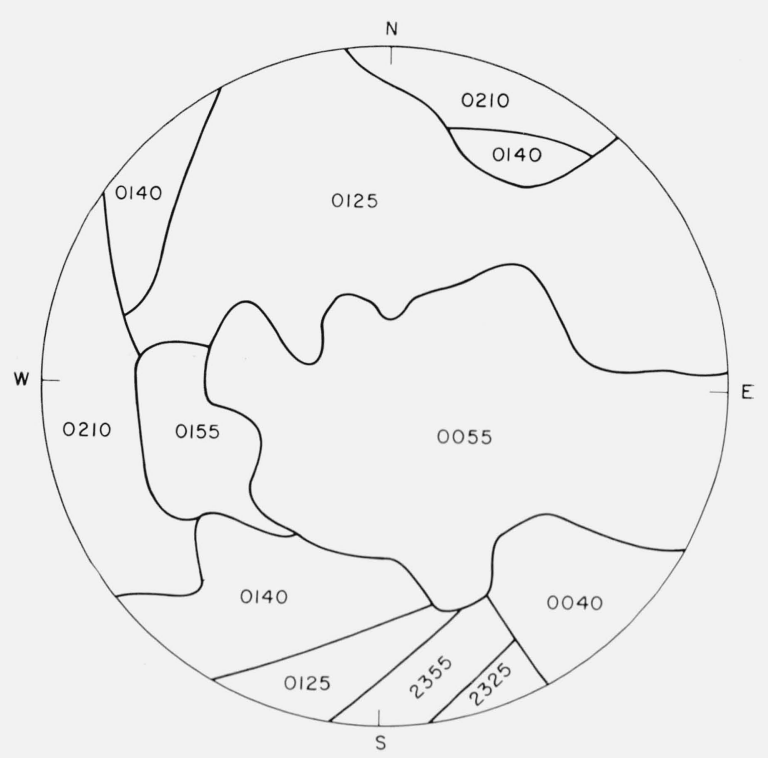

Figure 11. Times of maximum intensity. June 19/20, 1961.

\section{Summary}

Observations of the airglow at $6300 \mathrm{~A}$ at Haleakala have led to the following description of the observed phenomena for the months of May and June 1961.

1. In the zenith, well-defined intensity maxima are frequently observed. Times of the maxima are more or less randomly distributed throughout the night.

2. The zenith intensity is very well given by an empirical formula eq (6) involving the critical frequency and virtual height of the $F$ region of the ionosphere.

3. All-sky isophotal representations reveal that the intensity maxima seen at the zenith are manifestations of enhancements over relatively small areas, $500-1,000 \mathrm{~km}$ in diameter. These spots may appear in any part of the sky, to the north if before midnight and generally to the south after midnight. The spots seem to form and develop as a whole, in situ. They display some erratic motion but no progressive motion. The photometric changes seem to be associated with vertical movements of localized regions of the nocturnal $F$ layer.

We are especially indebted to S. Katehara of the Kihei (Maui) ionosphere station of the National Bureau of Standards for his cooperation in the measurement of ionograms for the nights of our photometric observations; also to H. M. Mann, C. M. Purdy, and G. A. Roach who obtained the photometric data on Haleakala. 


\section{References}

Barbier, D., Sur la correction de diffusion dans les mesures d'altitude des couches atmosphériques émettant la lumière du ciel nocturne, Ann. Geophys. 1, 144-156 (1944).

Barbier, D., La lumière du ciel nocturne en été à Tamanrasset, Compt. Rend. Acad. Sci. 245, 1559-1561 (1957).

Barbier, D., L'émission de la raie rouge du ciel nocturne et les propriétés de la couche $\mathrm{F}$ de l'ionosphère, Compt. Rend. Acad. Sci. 252, 3315-3316 (1961).

Barbier, D., Les variations d'intensité de la raie $6300 \AA$ de la luminescence nocturne, Ann. Geophys. 1\%, 3-15 (1961).

Barbier, D., and J. Glaume, Corrélations entre les intensités de diverses radiations de la luminescence atmosphérique nocturne, Ann. Geophys. 16, 56-76 (1960).

Barbier, D., and J. Glaume, Les radiations de l'oxygène 6300 et $5577 \AA$ de la luminescence du ciel nocturne dans une station de basse latitude, Ann. Geophys. 16, 319-334 (1960).
Barbier, D., G. Weill, and J. Glaume, L'émission de la raie rouge du ciel nocturne en Afrique, Ann. Geophys. 17, 305318 (1961).

Bates, D. R., and H. S. W. Massey, The basic reactions in the upper atmosphere, I., Proc. Roy. Soc. (London) A18\%, 261-296 (1946).

Delsemme, A. and D., La raie rouge du ciel nocturne a l'équateur, Ann. Geophys. 16, 507-524 (1960).

Purdy, C. M., L. R. Megill, and F. E. Roach, A new airglow photometer, J. Research NBS 65C (Eng. and Inst.), in press (1961).

Roach, F. E., L. R. Megill, M. H. Rees, and E. Marovich, The height of nightglow 5577, J. Atmospheric and Terrest. Phys. 12, 171-186 (1958).

Steiger, W. R., and J. W. Little, On the feasibility of a solar observatory in the Hawaiian Islands, Pub. Ast. Soc. Pacific 70, 556-560 (1958).

(Paper 66D2-181) 